\title{
Fabrication of Boron Nitride Dispersed Nanocomposites by Chemical Processing and Their Mechanical Properties
}

\author{
Takafumi KUSUNOSE \\ The Institute of Scientific and Industrial Research (ISIR), Osaka University, 8-1, Mihogaoka, Ibaraki-shi 567-0047 \\ 化学プロセスを用いた窒化ホウ素分散ナノ複合材料の作製とその特性 \\ 楠瀬尚史 \\ 大阪大学産業科学研究所, 567-0047 大阪府茨木市美穂ケ丘 8-1
}

\begin{abstract}
Hexagonal boron nitride (h-BN) dispersed nanocomposites were fabricated through a chemical process involving sintering of matrix ceramic powders covered partly with turbostratic BN (t-BN), which was synthesized by the reduction of a mixture of boric acid and urea precipitating on the matrix ceramic powder during drying after wet-ball milling. Silicon carbide $(\mathrm{SiC})$, silicon nitride $\left(\mathbf{S i}_{3} \mathbf{N}_{4}\right)$, alumina $\left(\mathbf{A l}_{2} \mathbf{O}_{3}\right)$ and aluminum nitride (AIN) were employed as matrix for $\mathrm{h}-\mathrm{BN}$ dispersed nanocomposites. The nano-sized $\mathrm{h}$-BN particles were found to be homogeneously dispersed within the matrix grains as well as at grain boundaries, which is typical of nanocomposite structures. As a result, the present nanocomposites showed unique and excellent properties such as high strength, low Young's modulus, high thermal shock resistance, and good machinability.
\end{abstract}

[Received December 1, 2005]

Key-words : BN, SiC, Nanocomposite, Thermal shock resistance, Machinability

1. Introduction

Ceramic materials have been recognized as having such disadvantages as low thermal shock resistance and hard machinability compared with metals, but several recent investigations have attempted to improve these properties in highstrength structural ceramics. ${ }^{\left.1)^{-7}\right)}$ Engineering ceramics like $\mathrm{SiC}, \mathrm{Si}_{3} \mathrm{~N}_{4}, \mathrm{Al}_{2} \mathrm{O}_{3}$, and $\mathrm{AlN}$ are viewed as prime candidates for structural materials in the 21 st century owing to their high strength, high wear resistance, high refractoriness, and chemical inertness. ${ }^{8)-10)}$ Moreover, in recent years, these ceramics have received considerable attention as materials for semiconductor manufacturing equipment owing to their high thermal conductivity and high corrosion resistance to plasma and halogen atmosphere. ${ }^{11)}$ However, their thermal shock resistance and machinability is still not sufficient for wider applications. In order to improve these properties, a number of researchers have looked into the possibility of adding h-BN as a second phase. ${ }^{12), 13)}$ However, while h-BN has high thermal shock resistance and good machinability, it has low fracture strength and Young's modulus. It has been reported that the fracture strength of the composites decreased remarkably with increased addition of h-BN due to the inhomogeneous dispersion of large, micron-sized BN particles and their agglomeration, even though thermal shock resistance and machinability were somewhat improved. ${ }^{14)}$ In the conventional fabrication of h-BN dispersed composites, commercially available h-BN powders with grain sizes of several micrometers are ball-milled with the matrix powders. ${ }^{12)-16)}$ It is difficult to disperse fine $\mathrm{h}-\mathrm{BN}$ particles in the matrix homogeneously by conventional mixing of commercial h-BN powders. Thus, the large h-BN particles and their agglomerates are thought to initiate fracture and decrease fracture strength of the composites because of their low Young's modulus and cleavage fracture. Hence, the fabrication of strong machinable ceramics with high thermal shock resistance was thought to be impossible. However, if it were possible to decrease the size of the h-BN particles and prevent their agglomeration, h-BN dispersed compo- sites could retain strengths matching those of monoliths. Thus, for h-BN dispersed ceramic composites, a nanocomposite structure, ${ }^{17)-20)}$ i.e., the homogeneous dispersion of nanosized h-BN particles in a matrix, would presumably be effective in enhancing the fracture strength. Also, thermal shock resistance can potentially be further improved by increasing fracture strength, in addition to preparing h-BN dispersion with low Young's modulus.

As mentioned above, it is difficult to disperse fine h-BN particles in a matrix powder homogeneously by using a conventional powder mixing method like ball-milling. Besides, a pure and fine h-BN powder is not commercially available. To solve these problems and obtain a nanocomposite structure, various processes based on precursors for nanocomposites have been developed. ${ }^{20)-22)}$ We sought a new synthetic method capable of yielding a microstructure with a homogeneous dispersion of h-BN within a matrix. Thus, we proposed a simple chemical process for precipitating an h-BN precursor, which is soluble in any ball-milling solvent and can readily transform into h-BN on matrix particles. ${ }^{23)-25)}$ Boric acid and urea are very suitable as boron and nitrogen sources for h-BN, respectively. Figure 1 shows a conceptual schematic of the chemical process. It has been reported that h-BN can be synthesized by reducing a mixture of boric acid and a nitrogen compound in hydrogen gas. ${ }^{23)}$

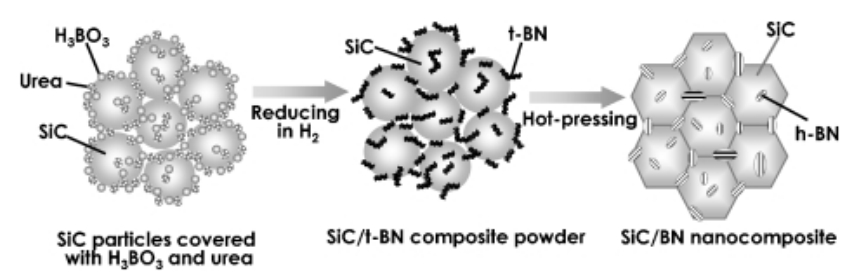

Fig. 1. Conceptual schematic of the chemical process for $\mathrm{BN}$ dispersed nanocomposites. 
The present paper reports the fabrication of $\mathrm{BN}$ dispersed nanocomposites, with $\mathrm{SiC}, \mathrm{Si}_{3} \mathrm{~N}_{4}, \mathrm{Al}_{2} \mathrm{O}_{3}$, or $\mathrm{AlN}$ used as matrix, by chemical processing, and their mechanical properties, such as strength, thermal shock resistance, and machinability.

\subsection{Sample preparation}

\section{Experimental}

The starting powders used as a matrix for h-BN dispersed composites were the commercially available $\beta$-SiC (Ultra Fine grade, Ibiden Co., Ltd., Gifu), $\alpha$ - $\mathrm{Si}_{3} \mathrm{~N}_{4}$ (SNE-10 grade, Ube Industries, Yamaguchi), $\alpha-\mathrm{Al}_{2} \mathrm{O}_{3}$ (AKP53 grade, Sumitomo Chemicals, Co., Ltd., Tokyo), or AIN (F grade, Tokuyama Corporation, Tokyo). This section will describe the chemical process used to fabricate the $\mathrm{SiC} / \mathrm{BN}$ composite as a typical example. Boric acid (Reagent grade, Wako Pure Chemical Industries, Tokyo) and urea (Reagent grade, Wako Pure Chemical Industries, Tokyo) were used as raw materials for the $\mathrm{BN}$ precursor. The $\mathrm{BN}$ content was adjusted to $5,10,15$, 20 and $30 \mathrm{vol} \%$. SiC powder, boric acid, and urea were mixed by the conventional wet ball milling method with $\mathrm{Si}_{3} \mathrm{~N}_{4}$ balls and ethanol in a plastic bottle for $24 \mathrm{~h}$ to ensure homogeneity of the powder mixture. Before drying, a small amount of ion-exchanged water was added to the slurry to dissolve the boric acid and urea completely and also to prevent boric acid from evaporating. The dried mixtures were reduced at $350^{\circ} \mathrm{C}$ for $3 \mathrm{~h}$ and at $1100^{\circ} \mathrm{C}$ for $8 \mathrm{~h}$ in hydrogen gas, and then heated at $1500^{\circ} \mathrm{C}$ for $5 \mathrm{~h}$ and $1650^{\circ} \mathrm{C}$ for $5 \mathrm{~h}$ in nitrogen gas to produce a $\mathrm{SiC}-\mathrm{BN}$ composite powder. The composite powders were ball-milled with the sintering aid $\left(7 \mathrm{wt} \% \mathrm{Al}_{2} \mathrm{O}_{3}+2 \mathrm{wt} \%\right.$ $\mathrm{Y}_{2} \mathrm{O}_{3}$ ) for $72 \mathrm{~h}$. After a second ball-milling run, the slurries were dried, and the powders were dry ball milled for $6 \mathrm{~h}$ to eliminate hard agglomerates. The composite powders were hot-pressed at $1850^{\circ} \mathrm{C}$ for $1 \mathrm{~h}$ in nitrogen atmosphere under an applied pressure of $30 \mathrm{MPa}$ to fabricate $\mathrm{SiC} / \mathrm{BN}$ nanocomposites. For comparison, a commercially available h-BN powder with an average grain size of $9 \mu \mathrm{m}$ (GP grade, Denki Kagaku Kogyo Kabushiki Kaisha, Tokyo) was used to produce microcomposites.

\subsection{Characterization}

The crystalline phase of the reduced composite powders and the hot-pressed samples were determined by X-ray diffractometry, using $\mathrm{Cu} \mathrm{K} \alpha$ radiation (Rigaku RAD-B, Tokyo). The microstructure was characterized by scanning electron microscopy (SEM, Model S-5000, Hitachi, Tokyo) and transmission electron microscopy (TEM, Model H-8100, Hitachi, Tokyo). The grain size distribution was estimated from SEM photographs of chemically-etched surfaces by using an image analysis technique. At least 1000 grains of $\mathrm{SiC}$ were measured for each sample.

Fracture strength was evaluated by three-point bending tests at room temperature. The tensile surfaces of specimens were perpendicular to the hot-pressing direction. The span length and crosshead speed were $30 \mathrm{~mm}$ and $0.5 \mathrm{~mm} / \mathrm{min}$, respectively. Young's modulus was determined by the resonance vibration method with first-mode resonance. Thermal shock fracture resistance was determined by measuring the bending strength of water-quenched samples. The samples were soaked for $10 \mathrm{~min}$ at a selected temperature in a vertical tube furnace and then dropped into a water bath at $20^{\circ} \mathrm{C}$.

Machinability of each composite was tested using a tungsten carbide $(\mathrm{WC} / \mathrm{Co})$ drill bit $1 \mathrm{~mm}$ in diameter. The drilling test was performed using a standard drill press operating at 660 rpm. The composite specimens were mounted on a load cell and tested by manually applying a constant normal force on

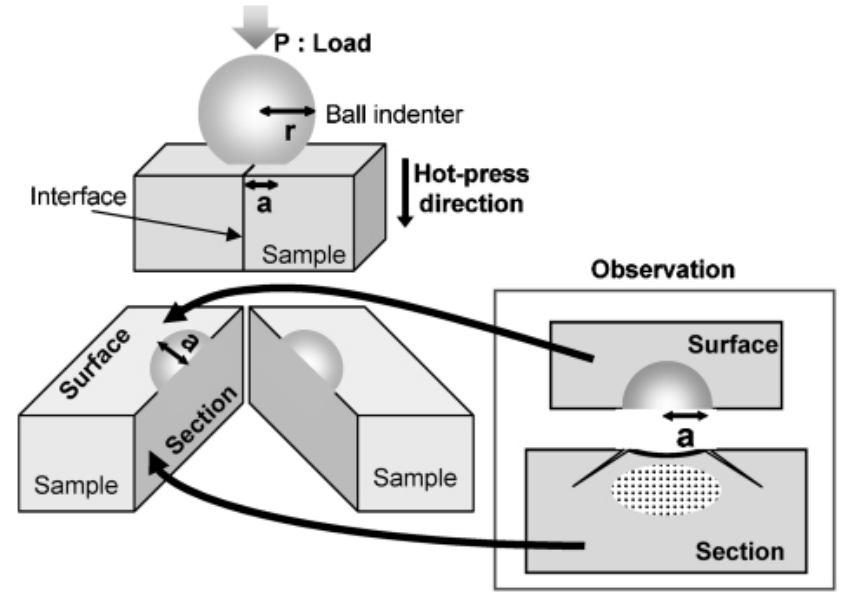

Fig. 2. Hertzian test geometry for bonded-interface specimen. Sphere, radius $r$, delivers load $P$ over contact radius $a$. Specimen consists of two polished halves bonded across the interface.

the drill under a load of $50 \mathrm{~N}$.

Ball indentations for the Hertzian contact test were made using WC/Co spheres of radii $r=1,1.5$ and $2 \mathrm{~mm}$, with a load range from $P=0$ to $1960 \mathrm{~N}$ using a universal testing machine (Autograph, AG-10TC, Shimadzu Co., Ltd.), as shown in Fig. 2. Contact radius $(a)$ at each applied load was determined by measuring the residual traces in the gold layer formed by ball indentation. Then, contact pressure $\left(p_{0}\right)$ was plotted as a function of indentation strain $(a / r)$ (see Fig. 12). Sub-surface contact damage induced by ball-indentation was examined using a bonded-interface technique, consisting of two polished half blocks joined by an adhesive. Indentations were made symmetrically across the traces of the interface at loads from 1470 to $1960 \mathrm{~N}$ with a tungsten carbide (WC) sphere of radius $1.5 \mathrm{~mm}$. After testing, the bonded materials were separated and the surfaces and sections cleaned with acetone. The polished specimens were viewed in an optical microscope using Nomarski interference contrast to reveal the macroscopic damage patterns, as represented in Fig. 2.

\section{Results and discussion}

\subsection{Fabrication of $\mathrm{SiC} / \mathrm{BN}$ nanocomposites}

Figure 3 illustrates the transformation of crystalline phases in the $\mathrm{SiC} / \mathrm{BN}$ composite fabricated by the chemical process using boric acid and urea as h-BN source. Since the starting powder before reduction in $\mathrm{H}_{2}$ consisted of $\mathrm{SiC}$, boric acid, and urea, it is thought that the boric acid and urea that precipitated onto $\mathrm{SiC}$ powders did not react during drying of the ball milled slurry. The reduced powder of Fig. 3(b) showed almost the same XRD pattern as the starting powder except for the disappearance of the peaks of boric acid and urea and the appearance of the extremely broad peak arising from turbostratic-BN ( $t-B N)$. This agrees with the XRD data for mixtures consisting of only boric acid and urea reduced by $\mathrm{H} 2$ under the same conditions. ${ }^{23)}$

Figure 4 shows the representative TEM pictures of the reduced powder corresponding to (b) in Fig. 3. It can be seen that the $\mathrm{SiC}$ particles are surrounded with a low contrast phase. On the basis of observation of the disordered layer using higher resolution TEM in Fig. 4(b) and the identification of boron using EDX, the reduced powder was found to be $\mathrm{SiC}$ partly covered with t-BN. It is well known that t-BN is transformed into $\mathrm{h}-\mathrm{BN},{ }^{26)-28)}$ analogous to the structural 


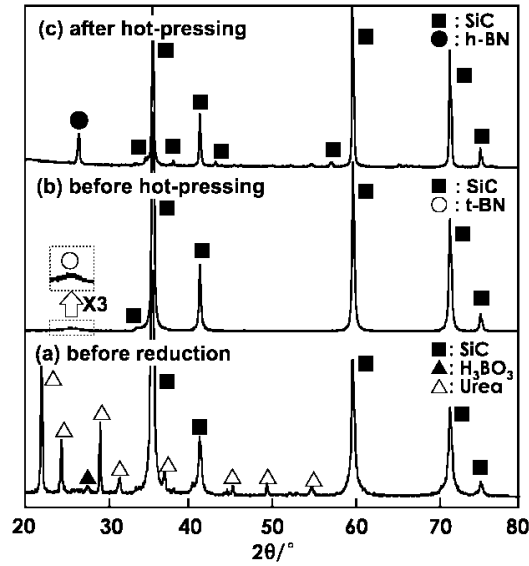

Fig. 3. XRD profiles of the powder mixture and sintered body of $\mathrm{SiC} / 10$ vol\% BN composite: $(\boldsymbol{\square}) \mathrm{SiC},(\boldsymbol{\Delta})$ boric acid, $(\triangle)$ urea, (○) t-BN, and (O) h-BN; (a) dried mixture before reduction, (b) powder mixture reduced at $350^{\circ} \mathrm{C}$ for $3 \mathrm{~h}$ and at $1100^{\circ} \mathrm{C}$ for $8 \mathrm{~h}$ in hydrogen gas, and then heated at $1500^{\circ} \mathrm{C}$ for $5 \mathrm{~h}$ and $1650^{\circ} \mathrm{C}$ for $5 \mathrm{~h}$ in nitrogen gas, and (c) compsite hot-pressed at $1850^{\circ} \mathrm{C}$ for $1 \mathrm{~h}$.
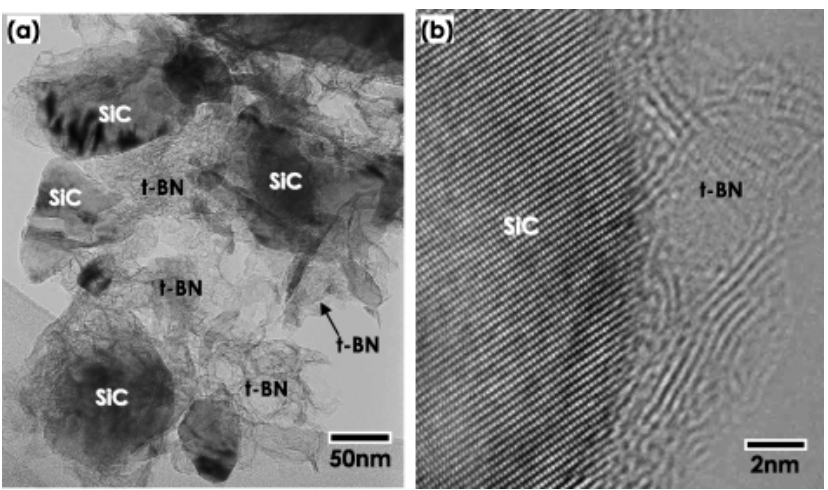

Fig. 4. TEM images of t-BN formed on the surface of $\mathrm{SiC}$ powder reduced at $350^{\circ} \mathrm{C}$ for $3 \mathrm{~h}$ and at $1100^{\circ} \mathrm{C}$ for $8 \mathrm{~h}$ in hydrogen gas, and then heated at $1500^{\circ} \mathrm{C}$ for $5 \mathrm{~h}$ and $1650^{\circ} \mathrm{C}$ for $5 \mathrm{~h}$ in nitrogen gas: (a) low magnification and (b) higher magnification.

change of graphite at $2000^{\circ} \mathrm{C}$ in nitrogen. Indeed, the broad peak of t-BN at around $25^{\circ}(2 \theta)$ in Fig. 3(b) evolved into the (002) peak of h-BN at $26^{\circ}(2 \theta)$ in Fig. 3 (c) during hot-pressing of the reduced powder at $1850^{\circ} \mathrm{C}$ for $1 \mathrm{~h}$ in nitrogen gas.

The sample studied could be identified as a composite consisting of $\mathrm{SiC}$ and h-BN in Fig. 3(c). Figure 5 shows a TEM image of the hot-pressed $\mathrm{SiC} / 10 \mathrm{vol} \% \mathrm{BN}$ composite produced via the chemical route. The nano-sized $\mathrm{BN}$ particles were homogeneously dispersed within the $\mathrm{SiC}$ grains as well as at grain boundaries. No apparent impurity phases were observed at the interface between $\mathrm{SiC}$ and intragranular $\mathrm{BN}$, which attained a graphite-like structure, as shown in Fig. 5 (b). Thus, it is concluded that $\mathrm{SiC} / \mathrm{BN}$ nanocomposites were successfully fabricated through the chemical process, followed by reduction and hot-pressing.

\subsection{Microstructure of SiC/BN nanocomposites}

Figure 6 shows the fractured surface of monolithic $\mathrm{SiC}$ and $\mathrm{SiC} / 10 \mathrm{vol} \% \mathrm{BN}$ composites. The microstructure of the large $\mathrm{BN}$ grains of the microcomposite were dispersed at grain boundaries of the SiC grains, whereas the nanocomposite exhibited a finer microstructure consisting of fine $\mathrm{BN}$ particles
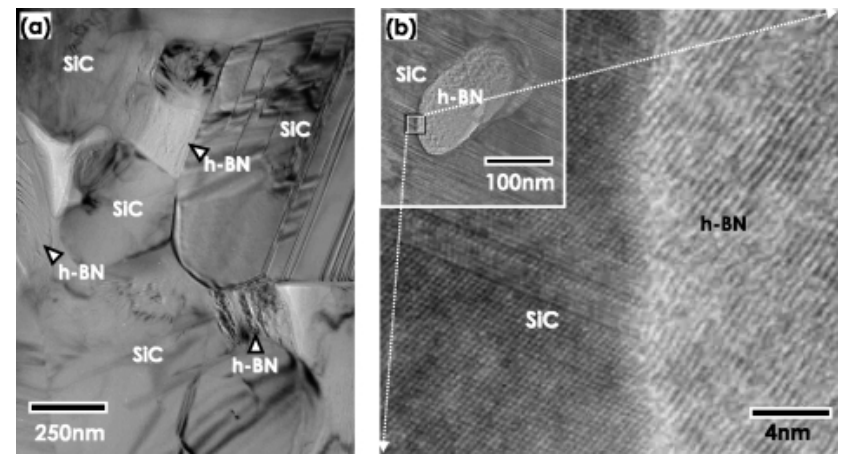

Fig. 5. TEM images of the hot-pressed $\mathrm{SiC} / 10 \mathrm{vol} \% \mathrm{BN}$ composite processed through the chemical route: (a) low magnification, and (b) interface structure between $\mathrm{SiC}$ matrix and intragranular h-BN particulate.
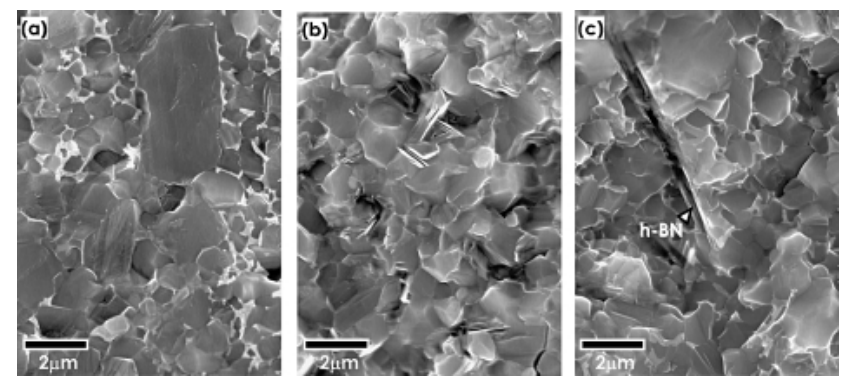

Fig. 6. SEM micrographs of fractured surfaces for monolithic SiC and $\mathrm{SiC} / 10$ vol\% BN composites: (a) monolithic $\mathrm{SiC}$, (b) nanocomposite, and (c) microcomposite.
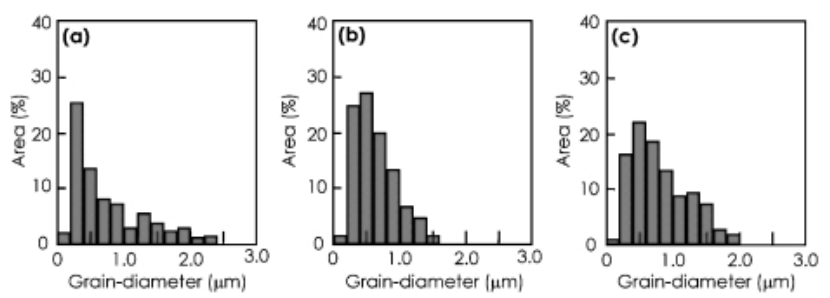

Fig. 7. Grain-diameter distribution for monolithic $\mathrm{SiC}$ and $\mathrm{SiC} /$ 10 vol $\%$ BN composites: (a) monolithic $\mathrm{SiC}$, (b) nanocomposite, and (c) microcomposite.

and micro-sized $\mathrm{SiC}$ matrix grains. The grain size distributions of $\mathrm{SiC}$ for monolithic $\mathrm{SiC}$, the $\mathrm{SiC} / 10$ vol\% $\mathrm{BN}$ microcomposite, and the nanocomposite are shown in Fig. 7. The monolithic $\mathrm{SiC}$ and the microcomposite have a wide grain size distribution, in which large $\mathrm{SiC}$ grains (diameter $>2 \mu \mathrm{m}$ ) were observed, but the nanocomposites exhibited a narrow size distribution in the fine grain end of the spectrum. These results agreed well with the SEM observations in Fig. 6. On the basis of these findings, we conclude that the finer BN particles markedly inhibited grain growth of the $\mathrm{SiC}$ matrix. This result can be supported by Zener's pinning effect, ${ }^{29), 30)}$ which suggests that, when the volume fraction of second phase particles is constant, the restraining force on grain boundary migration is inversely proportional to the radius of second phase particles. The inhibition of grain growth of matrix ceramics was observed not just in the case of $\mathrm{SiC} / \mathrm{BN}$ nanocomposites, but in other h-BN dispersed nanocomposites as well. ${ }^{23), 24)}$ 


\subsection{Young's modulus and fracture strength of $\mathrm{SiC} / \mathrm{BN}$} nanocomposites

Figure 8 (a) shows the variation of Young's modulus with $\mathrm{BN}$ content for the $\mathrm{SiC} / \mathrm{BN}$ composites. Young's modulus of conventional microcomposites and nanocomposites both decreased with increasing h-BN content, showing a low Young's modulus of $83 \mathrm{GPa}$.

Figure $8(\mathrm{~b})$ shows the variation in fracture strength with $\mathrm{BN}$ content for the $\mathrm{SiC} / \mathrm{BN}$ composites. In comparison with conventionally fabricated microcomposites, the nanocomposites fabricated by the present chemical process successfully retained a relatively high strength despite the decrease in Young's modulus due to the addition of soft h-BN (Young's modulus of h-BN and $\mathrm{SiC}$ are about 83 and $420 \mathrm{GPa}$, respectively). The fracture strength of the nanocomposites was approximately twice that of the microcomposites even at higher BN content.

According to Griffith theory, ${ }^{31)}$ the strength of brittle ceramics is controlled by the fracture toughness and the critical flaw size, which is strongly related to the size of $\mathrm{SiC}$ and/or h-BN in the case of $\mathrm{SiC} / \mathrm{BN}$ composites. Fracture toughness of the monolith and the nanocomposites containing 5-30 vol $\% \mathrm{~h}-\mathrm{BN}$ were both about $4 \pm 0.2 \mathrm{MPa} \cdot \mathrm{m}^{1 / 2}$. These values were relatively uninfluenced by the nano-sized $\mathrm{BN}$ dispersions. It is thought that the difference does not have a significant effect on enhancement of the fracture strength of the nanocomposite. However, the decrease in critical flaw size may have improved the fracture strength. As shown in Figs. 5 and 6 , the size of h-BN particles in the nanocomposites was much smaller than that in the microcomposites, and the matrix grain size of the nanocomposites was considerably refined by the nano-sized $\mathrm{BN}$ dispersions compared to the $\mathrm{SiC}$ monolith and the $\mathrm{SiC} / \mathrm{BN}$ microcomposites. Thus, it is concluded that the
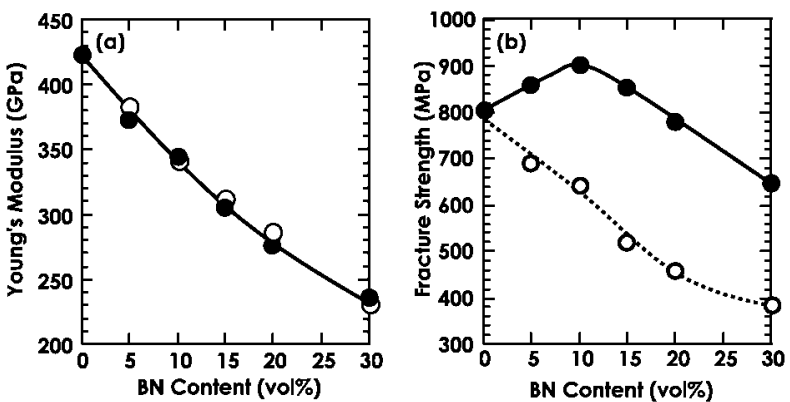

Fig. 8. Effect of h-BN content on Young's modulus (a) and fracture strength (b) of $\mathrm{SiC} / \mathrm{BN}$ composites: $(-\mathrm{SiC} / \mathrm{BN}$ nanocomposites and $(\bigcirc)$ microcomposites. observed high strength of $\mathrm{SiC} / \mathrm{BN}$ nanocomposites is attributable mainly to the reduction of the critical flaw size by the nano-sized h-BN dispersion. The mechanical properties of h-BN dispersed nanocomposites ${ }^{23)-25), 32)-34)}$ are summarized in Table. 1. It is found that all the produced h-BN dispersed nanocomposites have the unique mechanical property of high strength though low Young's modulus.

3.4 Thermal shock resistance of $\mathrm{SiC} / \mathrm{BN}$ nanocomposites

As described above, the nanocomposites fabricated by the chemical process showed relatively high strength despite the presence of BN dispersions with extremely low Young's modulus. Thus, a remarkable improvement in thermal shock resistance can be expected for this nanocomposite with high strength and low Young's modulus. Figure 9 shows the variation of residual strength after water quenching with the temperature difference $(\Delta T)$. The residual strength of monolithic $\mathrm{SiC}$ and 30 vol\% h-BN dispersed microcomposite decreased greatly at a $\Delta T$ of $380^{\circ} \mathrm{C}$ and $700^{\circ} \mathrm{C}$, respectively, whereas the $30 \mathrm{vol} \%$ h-BN dispersed nanocomposite did not show a sudden decrease in strength even at $1200^{\circ} \mathrm{C}$. A general and simple approach to estimate the thermal shock resistance of ceramic materials is given by following equation: ${ }^{35)}$

$$
\Delta T=\frac{\sigma_{\mathrm{f}}(1-v)}{E \alpha}
$$

where $\Delta T$ is the temperature difference above at which the residual strength shows a sharp decrease, $\sigma_{\mathrm{f}}$ is the strength, $v$ is Poisson's ratio, $E$ is Young's modulus and $\alpha$ is the thermal expansion coefficient of the material. As seen in this figure, the thermal shock resistance of the $\mathrm{SiC} / \mathrm{BN}$ nanocomposites was strongly improved compared with the microcomposites.

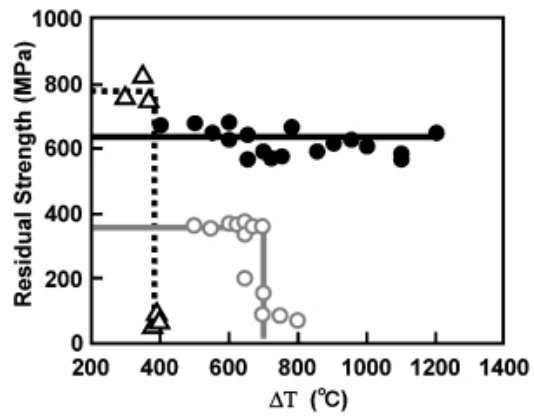

Fig. 9. Residual strength of monolithic $\mathrm{SiC}$ and $\mathrm{SiC} / 30 \mathrm{vol} \% \mathrm{BN}$ composites after water-quenching as a function of temperature difference, $\Delta T:(\triangle)$ monolithic $\mathrm{SiC},(\bigcirc)$ nanocomposite, and $(\bigcirc)$ microcomposite.

Table 1. Characteristics of h-BN Dispersed Nanocomposites and Microcomposites

\begin{tabular}{|c|c|c|c|c|c|c|c|c|c|}
\hline & \multirow{2}{*}{$\begin{array}{l}\text { BN contact } \\
(\text { vol } \%)\end{array}$} & \multicolumn{2}{|c|}{$\mathrm{Si}_{3} \mathrm{~N}_{4} / \mathrm{BN}$} & \multicolumn{2}{|c|}{$\mathrm{AlN} / \mathrm{BN}$} & \multicolumn{2}{|c|}{$\mathrm{Al}_{2} \mathrm{O}_{3} / \mathrm{BN}$} & \multicolumn{2}{|c|}{$\mathrm{SiC} / \mathrm{BN}$} \\
\hline & & Micro- & Nano- & Micro- & Nano- & Micro- & Nano- & Micro- & Nano- \\
\hline Strength (MPa) & 30 & 450 & 950 & 280 & 650 & 230 & 550 & 390 & 653 \\
\hline Young's modulus (MPa) & 30 & 205 & 207 & 170 & 170 & 220 & 220 & 231 & 222 \\
\hline \multirow{2}{*}{$\begin{array}{c}\text { Thermal shock resistance, } \\
\qquad \Delta \mathrm{Tc}\left({ }^{\circ} \mathrm{C}\right)\end{array}$} & 15 & 1350 & $1500<$ & --- & -- & 230 & 260 & --- & --- \\
\hline & 30 & --- & --- & --- & --- & --- & --- & 630 & $1200<$ \\
\hline Machinability & $20<$ & good & good & good & good & good & good & good & good \\
\hline
\end{tabular}




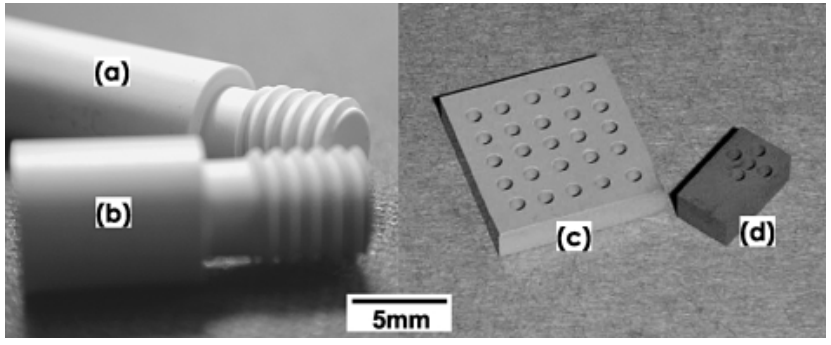

Fig. 10. Machining of the nanocomposites using WC/Co bits: (a) turning of $\mathrm{Al}_{2} \mathrm{O}_{3} / 30$ vol\% $\% \mathrm{BN}$, (b) turning of $\mathrm{Si}_{3} \mathrm{~N}_{4} / 30$ vol\% $\%$, (c) drilling of $\mathrm{Si}_{3} \mathrm{~N}_{4} / 20 \mathrm{vol} \% \mathrm{BN}$, and (d) drilling of $\mathrm{SiC} / 30 \mathrm{vol} \% \mathrm{BN}$.

Considering the physical properties related to Eq. (1), the improvement in thermal shock resistance for the nanocomposites is mainly attributed to the higher strength and lower Young's modulus caused by the dispersion of soft BN. As shown in Table 1, the thermal shock resistance of the $\mathrm{Al}_{2} \mathrm{O}_{3}$ / $\mathrm{BN}$ nanocomposite was improved only slightly, while those of the $\mathrm{Si}_{3} \mathrm{~N}_{4} / \mathrm{BN}$ and $\mathrm{SiC} / \mathrm{BN}$ nanocomposites were improved significantly.

\subsection{Machinability of h-BN dispersed nanocomposites}

It was difficult to machine h-BN dispersed composites containing less than $15 \mathrm{vol} \% \mathrm{BN}$ by using a WC/Co drill. However, as shown in Fig. 10, good machinability was observed in both h-BN dispersed microcomposites and nanocomposites containing more than $20 \mathrm{vol} \%$ BN. The nanocomposites, in particular, exhibited an excellent machinability comparable to that of metals, and retained their high strength. The difference in machinability between 15 and $20 \mathrm{vol} \%$ BN content is attributed to h-BN particles dispersed at grain boundaries. Intergranular, rather than intragranular, $\mathrm{BN}$ particles, are conductive to good machinability because intergranular fractures were frequently observed in the drilled surface of composites containing over $20 \mathrm{vol} \%$ of $\mathrm{BN}$. It has been reported that machinability is the result of the weak interface between matrix grains and second phases at grain boundaries. Morgan et al. and Hikichi et al. reported that even the considerably hard $\mathrm{ZrO}_{2}$ exhibited machinability owing to the easy grain detachment enabled by the incorporation of rare-earth phosphate into the microstructure, i.e., the weak interface between $\mathrm{ZrO}_{2}$ and rare-earth phosphate. The machinability observed in nanocomposites with high strength was probably achieved by grain detachment promoted by the weak interface between the hard matrix grains and fine intergranular h-BN particles with cleavage properties.

Figure 11 shows SEM micrographs of the drilled surfaces of $\mathrm{Al}_{2} \mathrm{O}_{3} / \mathrm{BN}$ microcomposite and nanocomposite materials containing a $30 \mathrm{vol} \% \mathrm{BN}$ dispersion as typical examples of h-BN dispersed composites. It appears that, in all samples, the intergranular fracture of $\mathrm{Al}_{2} \mathrm{O}_{3}$ grains was dominant, and the surface was partly covered with the debris of h-BN. These SEM micrographs reveal a significantly different micromechanism of material removal for the micro- and nanocomposites. In the microcomposite, the damage caused by drilling was very severe because of the larger crack path along microsized BN grains and their aggregates. As shown in Fig. 11 (d), large chippings of drilling track were observed in the drilled surface of the microcomposites. In contrast, the damage in the nanocomposites, characterized by the finer h-BN dispersion, was relatively minor. Furthermore, as can be seen from Figs. 3 (a) and (b), the drilling tracks in the nanocomposite were clearly visible, shallow, continuous grooves. These grooves
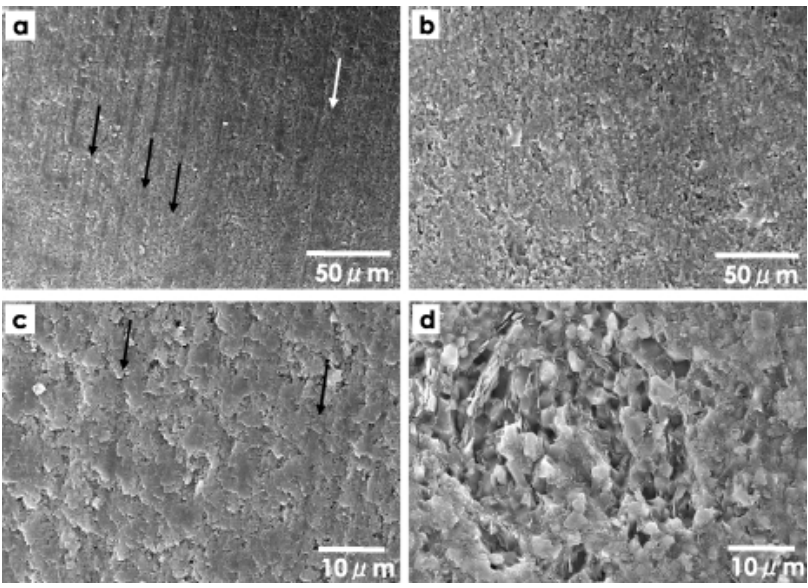

Fig. 11. SEM micrographs from surfaces of drilled holes in (a) (c) $\mathrm{Al}_{2} \mathrm{O}_{3} / 30$ vol $\% \mathrm{BN}$ nanocomposite $(\downarrow$ : direction of grooves by drilling) and (b) (d) $\mathrm{Al}_{2} \mathrm{O}_{3} / 30 \mathrm{vol} \% \mathrm{BN}$ microcomposite. (a) (b): Low magnification, (c) (d): high magnification.

formed by the sharp edge of the drill bit demonstrate good machinability that would presumably enable the nanocomposites to be formed into complex shapes. In the microcomposites, such sharp grooves were not evident because of the heavy damage in the drilled surface. The superior damage properties and machinability of the nanocomposites presumably result from the homogeneous dispersion of finer h-BN particles, which is expected to absorb and distribute the damage force during the machining operations by the many finer cracks formed along the grain boundaries.

3.6 Contact damage of h-BN dispersed nanocomposites Investigation of the contact damage of this nanocomposite is also interesting because to the unique microstructure in which extremely soft and weak second phase particles are homogeneously dispersed in a hard ceramic matrix. The Hertzian contact test developed by Lawn et al. is a simple experiment to determine the potential for absorbing a mechanical shock. In the present work, this test was performed in order to demonstrate the damage mechanism of each sample. Figure 12 shows indentation stress-strain curves for monolithic $\mathrm{Al}_{2} \mathrm{O}_{3}$ and $\mathrm{Al}_{2} \mathrm{O}_{3} / \mathrm{BN}$ nanocomposites containing 20 and $30 \mathrm{vol} \% \mathrm{BN}$ dispersions. The responses were obtained by monitoring the mean contact pressure $\left(p_{0}\right)$

$$
p_{0}=P / \pi \cdot a^{2}
$$

as a function of the geometrical ratio $a / r$, where $P, a$ and $r$ are the indentation load, the radius of contact and the sphere radius, respectively. The monolithic $\mathrm{Al}_{2} \mathrm{O}_{3}$ behaved as an ideal brittle material, with a near linear response up to $p_{0}=8.5 \mathrm{GPa}$. However, above that stress, the curve slightly deviated below the Hertzian line due to deformation of the WC/Co spherical indenter. In contrast, the curves of the $\mathrm{Al}_{2} \mathrm{O}_{3} / \mathrm{BN}$ nanocomposites containing 20 and $30 \mathrm{vol} \% \mathrm{BN}$ dispersions dramatically deviated from the linear response at $p_{0}=6$ and $5 \mathrm{GPa}$. On the basis of these responses of the monolith and nanocomposites, it was presumed that some deformation occurred at lower indentation stresses with increasing $\mathrm{BN}$ content. These results suggested that the deformation can be promoted by homogeneous dispersion of nano-sized BN.

Figure 13 shows the half-surface (upper) and side section (lower) of the Hertzian contact damage for an $\mathrm{Al}_{2} \mathrm{O}_{3}$ monolith and $\mathrm{Al}_{2} \mathrm{O}_{3} / \mathrm{BN}$ microcomposite and nanocomposite con- 


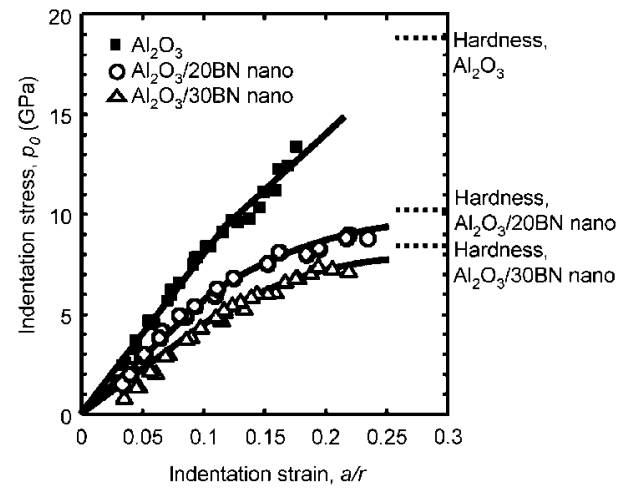

Fig. 12
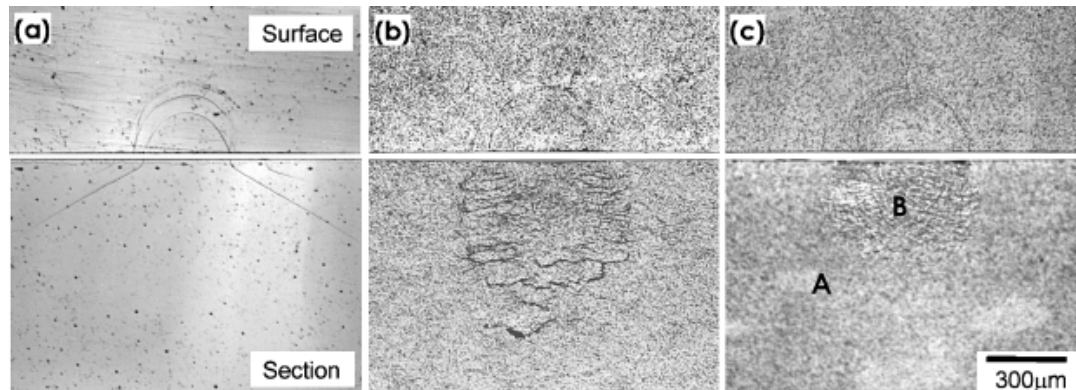

Fig. 13

Fig. 12. Indentation stress-strain curves for monolithic $\mathrm{Al}_{2} \mathrm{O}_{3}$ and $\mathrm{Al}_{2} \mathrm{O}_{3} / \mathrm{BN}$ nanocomposites, from Hertzian contact test. Data plotted for range of sphere radius $r=1-3 \mathrm{~mm}$. Solid curves are empirical fits to the data. Horizontal dashed lines indicate Vickers hardness for monolithic $\mathrm{Al}_{2} \mathrm{O}_{3}$ and $\mathrm{Al}_{2} \mathrm{O}_{3} / \mathrm{BN}$ nanocomposites.

Fig. 13. Optical micrographs of Hertzian contact damage in (a) monolithic $\mathrm{Al}_{2} \mathrm{O}_{3}$, (b) $\mathrm{Al}_{2} \mathrm{O}_{3} / 20$ vol\% $\mathrm{BN}$ microcomposite and (c) nanocomposite, showing half-surface (top) and section (bottom) views of subsurface deformation zone in bonded-interface specimens [see Fig. 1], at indentation loads (a) $P=1960 \mathrm{~N}$, (b) $1470 \mathrm{~N}$, and (c) $1960 \mathrm{~N}$. WC sphere radius $r=3 \mathrm{~mm}$.

taining 20 vol\% BN dispersion, respectively. The damage in the monolithic $\mathrm{Al}_{2} \mathrm{O}_{3}$ showed typical Hertzian cone fracture, in which the cone cracks propagate downwards and outwards into the specimen (Fig. 13(a)), and no detectable deformation besides the cone crack could be observed beneath the contact. This fracture pattern is indicative of a highly brittle solid. By contrast, there were many large cracks in the subsurface deformation zone of the $\mathrm{Al}_{2} \mathrm{O}_{3} / 20 \mathrm{vol} \% \mathrm{BN}$ microcomposite (Fig. 13(b)). These large cracks, which obviously differed from the classical Hertzian cone crack observed in the monolithic $\mathrm{Al}_{2} \mathrm{O}_{3}$, were formed by the propagation of cracks between large $\mathrm{BN}$ particles or agglomerates thereof.

In contrast to the above two materials, in the nanocomposite, the damage observed in subsurface deformation zone appeared to be quasi-plastic deformation, similar to the plastic deformation zone in ductile metals. This deformation accompanied the residual surface depression instead of a surface ring crack, which indicates the transition from brittle to ductile induced by the finer h-BN dispersion. The nanocomposite had a microstructure in which fine h-BN particles were homogeneously dispersed within $\mathrm{Al}_{2} \mathrm{O}_{3}$ grains as well as along grain boundaries. Thus, it is thought to be possible to distribute and absorb the stresses due to the ball-indentation through deformation and/or fine cracks originating from soft h-BN particles dispersed along the grain boundaries.

Figures 14 (a) and (b) show SEM micrographs of the non-deformed surface and quasi-plastic deformation zone of the ball-indented nanocomposite specimen. Significant grain boundary detachment was often observed in the damage zone. These observations suggested that the nano-sized intergranular BN particles weakened the bonding strength of the grain boundary. The quasi-plastic deformation zone, in which the microcracks were concentrated, was driven by a strong shear component at the grain boundary. It is thought that the quasiplastic deformation observed in the nanocomposites played an important role in their machinability. Quasi-plastic deformation by Hertzian contact test was observed in other h-BN dispersed nanocomposites such as $\mathrm{Si}_{3} \mathrm{~N}_{4} / \mathrm{BN}, \mathrm{SiC} / \mathrm{BN}$, and $\mathrm{AlN} /$ $\mathrm{BN}$.

\section{Conclusion}

The h-BN dispersed nanocomposites of $\mathrm{SiC} / \mathrm{BN}, \mathrm{Al}_{2} \mathrm{O}_{3} /$
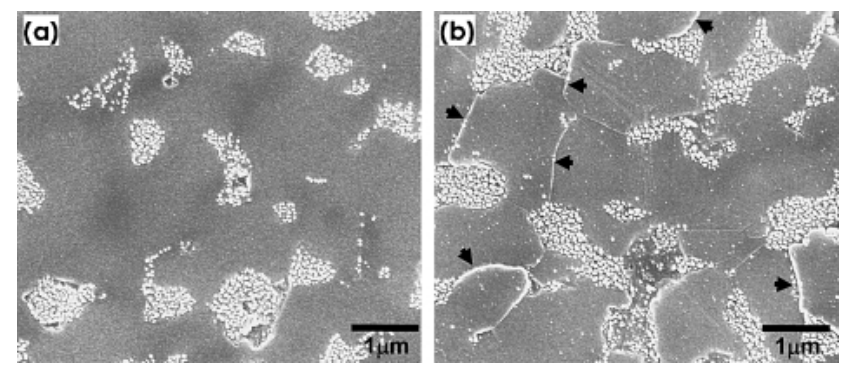

Fig. 14. SEM observation of subsurface damage in $\mathrm{Al}_{2} \mathrm{O}_{3} / 30 \mathrm{vol} \%$ $\mathrm{BN}$ nanocomposite: (a) quasi-plastic deformation zone [location $\mathrm{A}$ in Fig. 13(c) ], and (b) interface crackings of grain boundaries [location B in Fig. 13(c)].

BN, $\mathrm{Si}_{3} \mathrm{~N}_{4} / \mathrm{BN}$, and $\mathrm{AlN} / \mathrm{BN}$ were fabricated by sintering of nanocomposite powders, which are matrix powders coated partly with nano-sized t-BN. The matrix powders was coated with $\mathrm{t}-\mathrm{BN}$ via a chemical process, in which boric acid and urea as BN sources were precipitated onto matrix powders and heated in hydrogen atmosphere. The microstructure of the resultant composites showed a homogeneous distribution of nano-sized h-BN particles within the matrix grains as well as along the grain boundaries. Also, h-BN dispersed nanocomposites had finer and more homogeneous microstructures due to the inhibition of grain growth, compared with the monolith and the microcomposites. As a result, the Young's moduli of both micro- and nanocomposites decreased with increasing $\mathrm{h}$-BN content according to the rule of mixtures, but the strength of the nanocomposites was much higher than that of microcomposites. Additionally, owing to their high strength and low Young's modulus, the thermal shock resistance of h-BN nanocomposites was significantly improved compared with the monolith and the microcomposites. Moreover, nanocomposites containing more than $20 \mathrm{vol} \% \mathrm{BN}$ dispersion simultaneously attained high strength and good machinability. The damage caused by drilling in the nanocomposites was minor compared to that observed in the microcomposites. Although the contact damage of the monoliths was classical Hertzian cone crack, indicative of a highly brittle material, the 
nanocomposites showed quasi-plastic deformation, which is expected to absorb and dissipate the damage. This deformation zone was formed by microfractures that were caused by the weak interface between matrix grains and the nano-sized $\mathrm{h}-\mathrm{BN}$ particles along the grain boundaries.

Acknowledgments This study was supported by Industrial Technology Research Grant Program in '01 from New Energy and Industrial Technology Development Organization (NEDO) of Japan. The author would like to gratefully thank Prof. Koichi Niihara and Prof. Tohru Sekino for useful discussion, and Mr. Norikazu Tachibana, Mr. Takeshi Kawase, and Mr. Hideaki Fujiwara for experimental support.

\section{References}

1) Padture, N. P., Evans, C. J., Xu, H. K. and Lawn, B. R., J. Am. Ceram. Soc., Vol. 78, pp. 215-217 (1995).

2) Davis, J. B., Marshall, D. B., Housley, R. M. and Morgan, P. E. D., J. Am. Ceram. Soc., Vol. 81, pp. 2169-2175 (1998).

3) Kawai, C. and Yamakawa, A., J. Am. Ceram. Soc., Vol. 80, pp. 2705-2708 (1997).

4) Saraswati, V. and Raoot, S., J. Mater. Sci., Vol. 27, pp. 429-432 (1992).

5) Uno, T., Kasuga, T. and Nakayama, S., J. Ceram. Soc. Japan, Vol. 100, pp. 315-319 (1992).

6) Uno, T., Kasuga, T., Nakayama, S. and Ikushima, A. J., $J$. Am. Ceram. Soc., Vol. 76, pp. 539-541 (1993).

7) Uno, T., Kasuga, T. and Niihara, K., J. Am. Ceram. Soc., Vol. 74, pp. 3139-3141 (1991).

8) Mitomo, M., "Proceedings of the 1st International Symposium on the Science of Engineering Ceramics," Ed. by Kimura, S. and Niihara, K., Ceramic Society of Japan (1991) pp. 101-107.

9) Hirosaki, N., Akimune, Y. and Mitomo, M., J. Am. Ceram. Soc., Vol. 76, pp. 1892-1894 (1993).

10) Ohji, T., Hirano, T., Nakahira, A. and Niihara, K., J. Am. Ceram. Soc., Vol. 79, pp. 33-45 (1996).

11) Kusunose, T., Semiconductor Equipment Association of Japan, No. 98, pp. 50-51 (2005) [in Japanese].

12) Funabashi, T., Isomura, K., Harita, A. and Uchimura, R., "Ceramic Materials and Components for Engines," Ed. by Tenney, V. J., Am. Ceram. Soc. (1986) pp. 968-976.

13) Mazdiyasni, K. S. and Ruh, R., J. Am. Ceram. Soc., Vol. 64, pp. 415-418 (1981).

14) Goeuriot-Launay, D., Brayet, G. and Thevenot, F., J. Mater. Sci. Lett., Vol. 5, pp. 940-942 (1986).

15) Lutz, E. H. and Swain, M.V., J. Am. Ceram. Soc., Vol. 75, pp.
67-70 (1992).

16) Liu, H. and Hsu, S. M., J. Am. Ceram. Soc., Vol. 79, pp. 2452-2457 (1996).

17) Niihara, K., J. Ceram. Soc. Japan, Vol. 99, pp. 974-982 (1991).

18) Ohji, T., Jeong, Y. -K., Choa, Y. -H. and Niihara, K., J. Am. Ceram. Soc., Vol. 81, pp. 1453-1460 (1998).

19) Zhao, J., Stearns, L. C., Harmer, M. P., Chan, H. M., Miller, G. A. and Cook, R. E., J. Am. Ceram. Soc., Vol. 76, pp. 503-510 (1993).

20) Dusza, J., Sajgalik, P. and Steen, M., J. Am. Ceram. Soc., Vol. 82, pp. 3613-3615 (1999).

21) Herrmann, M., Schuber, C., Rendtel, A. and Hübner, H., J. Am. Ceram. Soc., Vol. 81, pp. 1095-1108 (1998).

22) Sternitzke, M., Derby, B. and Brook, R. J., J. Am. Ceram. Soc., Vol. 81, pp. 41-48 (1998).

23) Kusunose, T., Sekino, T., Choa, Y.-H. and Niihara, K., J. Am. Ceram. Soc., Vol. 85, pp. 2678-2688 (2002).

24) Kusunose, T., Kim, Y.-H., Sekino, T., Matsumoto, T., Tanaka, N., Nakayama, T. and Niihara, K., J. Mater. Res., Vol. 20, pp. 183-190 (2005).

25) Kusunose, T., Sekino, T., Kim, B.-S., Choa, Y.-H., Nomoto, T., Yamamoto, Y. and Niihara, K., Mater Science Forum, Vol. 439, pp. 131-136 (2003).

26) Brozek, V. and Hubaacek, M., J. Solid State Chem., Vol. 100, pp. 120-129 (1992).

27) Alkoy, S., Toy, C., Gonul, T. and Tekin, A., J. Eur. Ceram. Soc., Vol. 17, pp. 1415-1422 (1997).

28) Hagio, T., Nonaka, K. and Sato, T., J. Mater. Sci. Lett., Vol. 16, pp. 795-798 (1997).

29) Zener, C., quated by C. S. Smith: Grains, phase, and Interfaces: an interpretation of microstructure. Trans. Am. Inst. Min. Metall. Soc., Vol. 175, pp. 15-15 (1948).

30) Steans, L. C. and Harmer, M. P., J. Am. Ceram. Soc. Vol. 79, pp. 3020-3028 (1996).

31) Kingery, K. D., Bowen, H. K. and Uhlmann, D. R., Introduction to Ceramics, 2nd ed., John Wiley \& Sons (1976) pp. 783-787.

32) Kusunose, T., Sekino, T., Choa, Y.-H. and Niihara, K., J. Am. Ceram. Soc., Vol. 85, pp. 2689-2695 (2002).

33) Kusunose, T., Nomoto, T., Sekino, T., Kim, B.-S., Yamamoto, Y. and Niihara, K., J. Ceram. Soc. Japan, Vol. 111, pp. 821-825 (2003).

34) Kusunose, T., Choa, Y.-H., Sekino, T. and Niihara, K., Key Engineering Materials, Vols. 161-163, pp. 475-480 (1999).

35) Hasselman, D. P. H., Am. Ceram. Soc. Bull., Vol. 49, pp. 1033-1037 (1970).

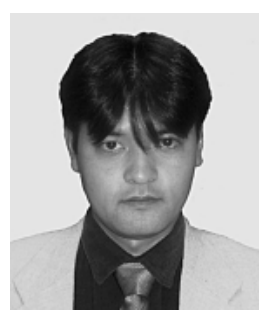

Takafumi KUSUNOSE is a research associate of The Institute of Scientific and Industrial Research (ISIR), Osaka University. He graduated from the Faculty of Science at Kochi University in 1994 and received his Master and Doctor degrees of Engineering from Osaka University in 1996 and 1999, respectively. He was JSPS Research Fellow in 1996 to 1999, a research associate of ISIR since 1999. His research interest is in nonoxide ceramic nanocomposite including powder processing, sintering, and properties. 